in diameter, extending diagonally over the papilla, not quite to its center. Diagnosis was made of sarcoma of choroid and immediate enucleation advised.

Patient did nothing for nearly two weeks and then consulted three eminent colleagues, all of whom pronounced the separation as probably not due to a tumor, though one proposed a needle operation for purpose of diagnosis, which was refused. This means that the separation had extended greatly during the two weeks, as there was no question as to the diagnosis October 9. January 19 patient again consulted a colleague, presenting iridocyclitis and a glaucomatous condition. Enucleation was performed Feb. 1, 1891, and a choroidal tumor of 5 $\mathrm{mm}$. in diameter found, of uniformly black color, composed of small spindle cells without reticulum and numerous large pignent cells. Later, patient came again under my observation ind remained there for six months. There was no recurrence il. the orbit of the sarcoma, but the patient began gradually to fail ; six months after the operation, went away for his health and died within eighteen months of "liver trouble." No post mortem.

Case 3... Mrs. M. presented herself Sept. 16, 1893, with a history of poor vision in right eye for several months. Vision equals fingers in the outer field at two feet. Separation of the retina involving all but the outer upper and inner upper portion of the retina. Optic nerve not visible. No tension and no iritis or cyclitis. Media clear and the retina apparently pushed forward by a large, dark, rounded mass growing from the outer central portion of the choroid.

Diagnosis : Melano-sarcoma, and I enucleated September 20. The tumor was round, $7 \mathrm{~mm}$. in diameter, not extending to the papilla ; composed of spindle cells, round granular and pigment cells. Optic nerve showed no infiltration nor did specimen from the connective tissue of the orbit. Jan. 1, 1896, there had been no recurrence; patient in normal condition.

Case 4.-Mr. E. C., merchant, aged 56, came Nov. 6, 1893, with a history of poor vision in right eye since May 1893. Old corneal scar from blow with a marble at ten years of age. Counts fingers at five feet. Separation of the retina nearly complete, except in upper inner quadrant. Ophthalmoscope reveals a mass reaching nearly to the iris in front growing from the outer upper portion of the field, covered by the retina still showing the retinal vessels. Enucleation advised, with diagnosis of sarcoma of choroid. I operated Nov, 17, 1893, and found tumor of $4 \mathrm{~mm}$. diameter, having its origin $6 \mathrm{~mm}$. from the papilla. Tumor had a very small base, was a spindlecelled sarcoma with some pigment. Patient's condition Jan 20,1896 , good, health excellent, with no sign of recurrence.

Case $5 .-M r$. C. K., business man, age about 48, consulted me November 28,1893 , with the request that I give him a pair of glasses.

O. D. -1 D. Cyl., 160 deg. $5 \cdot 6$ Sz. Partly.

O. S. -0.50 D. Cyl., 160 deg. 5.5 .

The day was rather dark and vision so good that it was only a fixed habit which led me to examine the fundus, when $I$ was greatly surprised to find a small tumor on nasal side near the macula, with retina pushed forward and adherent to the tumor ; no separation of the retina extending away from the base of the tumor.

Diagnosis: Sarcoma. The patient lost a brother from carcinoma of the tongue. Patient went to Brooklyn for operation at the hands of a friend who is a specialist and the eye was enucleated Dec. 5, 1893.

The following is the report of the pathologist at the New York Hospital : "The tumor is almost spherical in shape. It originated in the loose connective tissue of the suprachoroidal space and involved the entire choroidal layer and external layer of retina, pigment layer, rods and cones, mebrana limitans externa and extended a short distance on either side in the external molecular layer of the retina, the other layers of the retina are pushed before the tumor and can be recognized as a thin membrane everywhere limiting the tumor in front. Posteriorly it is limited by the sclerotic, which at the point of contact with the tumor is only one-half the normal thickness. The tumor is $7 \mathrm{~mm}$. in diameter. It is estimated that the center of the tumor is $5 \mathrm{~mm}$. from the physiologic excavation. It is composed of spindle cells of medium size, spindle-celled sarcoma, with a minimum amount of basement substance. The vascular supply is quite abundant. There are pigment granules throughout, but it can not be regarded as a melanotic sarcoma. Along the course of one or two of the vessels in the sclerotic coat are numerous round and spindle-form cells, but can not be identified as sarcomatous elements. The optic nerve, dural sheath and external sheath show no evidence of tumor tissue."

Feb. 29, 1896, patient's health perfect ; no sign of recurrence.

There are in addition to the above five cases, of which I have been able to give more or less complete histories. two cases in my record books which I have not been able to report; one where the diagnosis was quite certain and whose history I hope to give later, and another where it is a question as to whether there is a tumor under the separation of the retina or not.

Of the above five cases two died, one certainly and the other probably as a result of a recurrence of the sarcoma in other parts of the body. Both cases where death ensued were rapid in progress and had reached the stage of glaucoma and involvement of the ciliary body.

The report is presented for the purpose of a discussion as to the practical questions which present themselves.

1. The question of early diagnosis between the separation of the retina and the separation of the retina which is caused by a tumor behind it.

2. The question as to whether enucleation shall be advised in cases where the diagnosis is not certain.

3 . The importance and duty of assisting one another by giving to each patient, in all cases of doubt, i. e., in almost all cases of ablatio retinæ, full notes and sketches for use when patients consult other specialists, which is usually the case.

First, as to diagnosis: This is often easy when the tumor can be seen, or where glaucomatous symptoms or inflammations of the ciliary body, have presented themselves, also where the separation follows extreme myopia, or a blow, or injury, or seasickness. Where the separation is slight and occurs in the upper half of the field, the tendency of the sub-retinal fluid to seek the lowest level will often assist the diagnosis, and in some cases drawing off the fluid with a hollow needle and syringe will clear up the doubt even though the separation is not cured by that means.

The importance of early diagnosis is greatly increased by the fact that these choroidal sarcomas aimost always occur as primary and not as metastatic sarcomas. I have not found in the literature a single case of a sarcoma or melano-sarcoma occurring as a metastasis following sarcoma in some other portion of the body. On the other hand, particularly in the case of melano-sarcoma, metastases in other parts of the body following the sarcoma in the eye-ball are very frequent and fatal.

Second, as to indications for an operation in cases of doubt, I would suggest enucleation be advised where: $a$, the vision is irrevocably destroyed and there is doubt as to the presence of a tumor; $b$, where, though there is slight vision present, it is failing rapidly through extension of the separation, and there are no previous examinations by colleagues, excluding the presence of a tumor, with no good reason for excluding it from the history of the case; $c$, where glaucomatous symptoms show themselves or cyclitis or irido-cyclitis.

\section{DERMOID TUMORS OF THE CORNEA.}

Read in the Section on Ophthalmology, at the Forty-seventh Annur Meeting of the American Medical Association, at Atlanta, Ga., May 5-8. 1896.

BY ALBERT RUFUS BAKER, M.D.

Professor of Diseases of the Eye, Ear and Throat. in the Cleveland College of Physicians and Surgeons, Medical Department of the Ohio Wesleyan University, Cleveland, Obio.

Although a number of cases of dermoid tumors of the cornea have been reported from time to time it has seemed to me that a brief report of the only two cases that have come under my observation might be of sufficient interest to claim your attention. 
Case 1.-July 1880, Mr. M. G., aged 24, a peculiar growth from the cornea of left eye, protruding between the lids, preent since birth, pedunculated, occupying the entire palpebral opening, measuring about one inch in length by one-half inch in breath, and rather thickly studded with stiff black hair. Being pressed together by the eyelids, the tumor presented upon superficial inspection the appearance of a small hair brush instead of an eye. The eyeball was entirely concealed by the growth, but by opening the lids widely and pushing it downward some clear cornea could be seen, and fingers counted. Patient declined operation at that time but returned in 1884. He thought the tumor was growing larger but it seemed to me about the same size as when first seen. An anesthetic was given and the tumor removed without difficulty. It was found to be attached to a little more than half of the cornea at its lower and outer portion, but peeled off smoothly, leaving a transparent cornea beneath.

It extended close up to the sclero-corneal margin but did not encroach much, if any, upon the conjunctiva, with which it seemed to be intimately connected. The portion of the cornea occupied by the tumor became somewhat cloudy for a few days but soon cleared up excepting a small line running in a semicircle across the cornea, marking the point of attachment; vision fairly good : is able to read ordinary book print.

Case 2.-July 15, 1893, Miss A. P., aged 17, three small flat dermoid tumors of cornea of left eye. Two of them were on the outer sclero corneal margin and each about one-third the diameter of the cornea ; the other a small one consisting of a fine line extending perpendicularly across the pupillary area almost at the center of the cornea. The three tumors were all separated by clear cornea. They had the appearance of ordinary integument with a slightly pinkish tinge. Present since birth and no increase in size. Patient was seen by Dr. C. R. Agnew in 1877. It seems to me that $I$ have seen a report of the case by Dr. Agnew, but I have been unable to find it in the literature at my command. Under a general anesthetic I dissected off the tumors. Was very glad I gave a general anesthetic at the urgent solicitation of the patient because of the free hemorrhage which would have embarrassed me very much with cocain alone. The case made an uneventful recovery, but with much more opacity of the cornea than I had hoped, judging from my experience with the other case. There was a high degree of hypermetropic astigmatism and with full correction vision was only brought up to $20-200 \mathrm{~S}$.

Ryba $^{1}$ in 1853 collected twenty-seven cases that had been reported up to that time in human eyes; three in oxen's and four in dogs' eyes. Mr. Dixon reported a case of dermoid tumor the size of a hazel nut upon the lower part of the cornea and sclerotic of a little girl. The tumor was removed and found to be white. smooth and hard. The cornea after removal was transparent but in three or four days became white and opaque.

Cases have been reported by Graefe $;^{3}$ Virchow, ${ }^{4}$ Arlt, ${ }^{5}$ Taleferro ${ }^{6}$ Hulke, ${ }^{7}$ Wells, Labrum, Cooper, ${ }^{16}$ Strawbridge, ${ }^{11}$ Risley, ${ }^{12}$ Roberts, ${ }^{13}$ Fuchs, ${ }^{14}$ Brose, ${ }^{15}$ and others.

Ammon ${ }^{16}$ reports a case of coloboma of eyelids in which a dermoid tumor of the cornea filled the gap.

$\mathrm{Mr}$. Swanzy ${ }^{17}$ gives detail of a case he observed under the care of Von Graefe. The tumor was very large and was removed by Graefe. It occupied the whole of the depth of the cornea. The anterior chamber was opened and considerable vitreous escaped.

Milvalsky ${ }^{18}$ (Prague) reports two cases of dermoid tumors of the eyeball. The paper is published in Cezechesh with a résumé in French. The author has reviewed the literature on the subject very carefully and has found recorded seventy-five cases of dermoid tumors of the eye-ball. Seven of these he calls atypical, being connected with the eyelids. Five of the cases were entirely corneal, and twelve were situated on the sclerotic and fifty-one were placed partly on the sclerotic.

"The relation of these tumors to the conjunctiva varied. In some the conjunctiva seemed to be replaced by the tumor tissue: in others it covered the surface of the latter, while in most instances a portion of the growth was apparently covered by conjunctiva, while the remainder exhibited on the surface a pavement epithelium, papilla, hair follicles and fine hair. The cystic form or closed dermoid is never met with in the eye."

A review of the preceding cases seem to show that they are all congenital; a few may be located on the cornea alone, a few on the sclerotic but the largest number involved both structures and are found most frequently at the outer and lower sclero-corneal margin.

Van Dusyse's ${ }^{19}$ ingenious theory as to the origin of these tumors is not generally accepted, namely, that the amnion was at one time united and through constriction and separation, there remained at the original point of contact amniotic cells from which later the dermoid cysts developed." A more reasonable explanation is the one generally accepted as to the etiology of dermoid growths in other parts of the body, i.e. an inversion of the epiblast during embryonic existence, an islet deposit of cells, which makes skin, sebaceous glands and hair follicle.

Little need be said as to treatment. Removal for cosmetic purposes is usually desirable. Notwithstanding Von Graefe's unfortunate experience the danger of penetrating the eyeball is slight. It does not seem to me that cauterizing the wound as recommended by most writers is necessary, and may only add to the amount of opacity present upon recovery. The same objection is true with regard to the advisability of covering the surface of cornea exposed with conjunctiva, recommended by some writers.

BIBLIOGRAPHY.

I Ryba: Prager Viertel Jahrschrift, 185:3, Bd. 3 p. I 1895 .

Graefe: Archiv f. Ophthalmologie, vir, p. 3, x p. 214

Virchow: Archiy f. Pathologische Anatomie, 6 Band, Heft 4, p. $5 \overline{5}$. Arit: Krankhendinches Binde \& Hornbaut, p. 170 .

Taleferro: Amerlat July, 1841, p. 88 wrence on the eye, p. 341.

Hulke: Ophthalmic Hospital reports, Vol. III, p. 332.

. 232 10)

11 Strawbridge: American Journal of Medical Seience, i873. p. 106-107.

12 Risley: P'hiladelphia Medical Times, 1879-80, p, 490.

13 Roberts: Philadelphia Medical Times, $1879-80$, 490.

4 Fuchs: Text Book Ophthalmology, p. 115. Klin. Monats. f. Augenh. tuttgart. 1880 , x viI, p. 131-134.

15rose: Archives of Ophthalmology, October 1895, p. 479

16 Ammon: Kliniscbe Darstellungen, Yt. 2. Tab. 1, Fgs. \& \& 9

1) Swanzy: Dublin Quarterly Journal of Medicine, May 1871, Royal ondon Ophthalmic Hospital Reports.

8 Milvalsky: Ophthamic Review, Vol. vil, p. 217.

19 Yon Jusyse: Ann. Soc. de Med. de Grand, 1882, Lx, p. 170-206. Also Ann. d' Ocul. Brux., 1S82, LXXXVIII, p. 101.132.

\section{DISCUSSION.}

Dr. A delaide E. Portman, Washington-From the situation it can be readily" understood why it is so serious in removal as it involves the whole depth of the cornea and the sclerotic, removal causing results to visual acuteness. Hirschberg reports $a_{-}^{-}$case, in a girl of 17 , of enormous size in which the result was vision of normal acuteness.

Dr.J. A. WHITE, Richmond-I reported a case of dermoid grow th of the cornea in a man some years ago. The growth was so large as to prevent closure of the lids, the cornea being entirely covered and the sight in consequence abolished. It had begun at the corneal margin some ten years previously and gradually overspread the cornea in which by pressure it had produced ulceration, followed by cicatricial adhesions over one-third of its surface. Its romoval was followed by favorable healing, the cornea cleared and subsequently the eyesight became nearly normal. This tumor was not congenital but was shown. by the microscope to be a dermoid growth.

Dr. D. S. Reynolds, Louisville-The technique of the operation is vastiy more important than the study of the comparative 
rarity of dermoid growths of the cornea. Any growth of this circulation or mobility of any kind. "It forms the kind which invades the sclerotica must make any attempt at liquid element of the secretions through the medium complete removal fatal to vision by the inevitable cyclitis of dissolving and enabling the digested food to pass which ensues. A comparatively large growth located entirely into the system and the effete products to pass out: a in the cornea may be safely removed. In the case of a man constant ingress and egress are occuring, and the who lost the fellow eye, I removed a large dermoid tumor of former requires to stand in proper adjustment to the the cornea, closing the wound by the Lembert suture, with the result of restoring such useful vision as enabled the man to go about alone. If the sutures penetrate the whole thickness of the cornea the openings through which the sutures pass will continuously drain away the aqueous humor, keeping the sutures so long in contact with the surface of the iris as to lead to its fatal inflammation.

\section{WATER}

BY I. N. LOVE, M.D.

$$
\text { sт. LOUIS, Mo. }
$$

In searching for the striking and unusual we often overlook that which is trite and commonplace to our detriment. Nowhere is this more true than in the practice of medicine. I believe that we are, safe not only as teachers in medicine but among ourselves, in laying stress upon the importance of using the simplest possible means for gaining a given end. The neophyte is not the only one who seeks for the unusual, for the formidable, as a means to an end and overlooks that which is near his hand. Indeed. all of us are prone to err in the same direction. As a profession we need to call a halt, ever and anon to get down off of our stepladder in our search for the unattainable, to come down to terra firma and use the things that nature has given us. Drugs, drugs, drugs, seem to be the chief inspiration in the life work of too many medical men, and in these modern days we must have a care in our use of animal therapy, for we know not as yet but what this form of medicine is quite as dangerous, if not more so, than the articles belonging to the mineral and vegetable kingdom; the drugs of which Oliver Wendell Holmes very truly said, "That the world at large would be better if they were all thrown into the sea," but the fishes would more than likely cease to be, as a result of the dumping.

Water, which is everywhere near at hand, ready for use, is one of the most important remedial meas. ures we can bring into play. The hydropaths, who for long were loolzed upon as fanatics, have done humanity and the medical profession a service, in that they have demonstrated the great value of water. However, the fanatic in the use of one remedy oftentimes is in danger of denying his patient remedies of value that would work in harmony with his special hobby. Surely, when we recall the fact that more than 75 per cent. of the whole make-up of the human body (including every tissue of the same) is water, we can appreciate its importance. It has been demonstrated, time out of mind, that while water fulfills many other subsidiary offices, it is essential for the occurrence of molecular change, or mobility - the essence of the manifestations of life. In the absence of water a state of molecular rest (which means the absence of activity) prevails.

It goes without saying, that water in some shape or other, is one of the essential conditions of life and just as essential as solid matter, it not only entering into a constitution of every part of the body, but is required for various purposes in the performance of the operations of life. Without it there could be no

Read at the meeting of the Mississippi Valley Medical Association, St. Prul, Minn., Sept. 18, 1896.

\section{latter. The demands for water are effected by the} amount of muscular exercise and the degree of temperature to which the individual is exposed, as in both conditions the loss through the skin as well as through the lungs is greatly increased." It has been a popular impression for long that the drinking of water with the meals interferes with digestion in diluting the gastric juice, and as a result of this notion, the public have largely refrained from drinking water with their meals. Pavey well says that it is a mistaken notion to think that when we drink with a meal we are diluting the gastric juice. The act of secretion is excited by the arrival of the meal into the stomach, and the gastric juice is not there at the time of ingestion. It happens indeed that the absorption of fluid takes place with great activity and the liquid drunk during the meal (unless the quantity be very great) becoming absorbed may be looked upon as proving advantageous by afterward contributing to yield the gastric juice which is required.

For an irritable stomach or an attack of so-called bilious colic, nothing is superior to liberal quantities of hot water as pure as possible. The first amount administered may be rejected, but if so, it accomplishes the washing out of the stomach. If the drinking be persisted in, a large quantity will be retained and finally a relaxation of the pyloric orifice of the stomach will occur, and the water will pass freely into the smaller bowel, relaxing and stimulating secretion as it goes. The intense pain of these attacks can often be promptly relieved and if helped by the addition of hot water applied over the stomach and bowels, through the medium of cloths saturated with the same, and occasionally sprinkled with small quantities of turpentine, which acts as a counter irritant. In the majority of cases the stereotyped administration of morphin by injection, is uncalled for. Indeed we are safe in saying that in the bulk of the attacks of acute indigestion and intense pain resulting therefrom, we had better relieve the condition in the simple manner suggested, rather than apply remedies which deaden pain, check secretion and retard convalescence, and frequently mask the preliminary symptoms of a dangerous disease. Nothing will more promptly relieve a patient's suffering from the after-effects of a banquet or midnight dinner, where the victim has possibly tarried with and looked too long upon the wine which is red (and white wine too for that matter) resulting in the dark brown taste and that terribly different feeling in the morning, than the imbibition of large quantities of hot water. The instruction to drink one or two pints of extremely hot pure water, prior to rising and sandwiching in between the various glasses a cup of black coffee, without cream or sugar, will give us a good result. The hot water washes out the stomach from above downward, stimulates the activity of the excretory glands, soothes and tranquilizes the nervous system, which is thoroughly on edge, and the black coffee administered in the manner suggested, meets the necessities of the hungering and the exhausted nerve centers, serves as a disinfectant for the alimentary 